\title{
EFFECT OF 1,2,4-TRIAZINE DERIVATIVES ON THE MOSQUITO "CULEX PIPIENS" AND ITS BIOLOGICAL CHARACTERISTICS
}

\author{
Walaa Nagaa $^{\dagger}$; Mohamed Shahen ${ }^{\dagger *}$; Mohamed A. Soliman; Wesam S. Meshrif \\ Zoology Department, Faculty of Science, Tanta University, Gharbia, Egypt
}

\author{
Article History: \\ Received: 16 November 2021 \\ Revised: 20 December 2021 \\ Accepted: 21 December 2021 \\ Published Online: \\ 31 December 2021 \\ Keywords: \\ Culex pipiens \\ Insecticides \\ Mosquito biology \\ Pymetrozine \\ Triazine derivatives \\ *Correspondence: \\ Mohamed Shahen \\ Zoology Department \\ Faculty of Science \\ Tanta University \\ Tanta, Gharbia, Egypt \\ E-mail: \\ mshahen@science.tanta.edu.eg \\ ${ }^{\dagger}$ Equal contribution
}

\begin{abstract}
Vector control is a serious concern in developing countries such as Egypt. The present study has been carried out to evaluate the larvicidal activities of 1,2,4-triazine derivatives against $3^{\text {rd }}$ larval instar of the mosquito "Culex pipiens" under laboratory conditions. To achieve this aim, the median lethal concentrations $\left(\mathrm{LC}_{50}\right)$ of the tested compounds and their effects on larval development and adult emergence were assessed. Adult females' fecundity and egg hatchability were estimated on the survivors of treatment. It was evident that 1,2,4-triazine compounds have a toxic effect on $C x$. pipiens. The estimated $\mathrm{LC}_{50}$ values of 1,2,4-triazine were $0.457,0.333$, and $2.047 \mathrm{mg} / \mathrm{L}$ for MSA 35, MSA 102, and the reference insecticide "pymetrozine", respectively. One week after treatment, both the compounds MSA 35 and MSA 102 were more effective (higher mortality rate and shorter lethal time) than the reference insecticide. The $\mathrm{LC}_{50}$ of MSA 102 induced a significant prolongation in the development time and less adult emergence compared with the control. Moreover, adult females surviving the treatment of MSA 102 as larvae, laid no eggs, while those treated with MSA 35 showed reduced hatchability compared with the control. In conclusion, the larvicidal potency of the tested 1,2,4-triazine derivatives is suitable for application against $C x$. pipiens mosquitoes and supposed to be a new alternative to other commercial insecticides like pymetrozine.
\end{abstract}

\section{INTRODUCTION}

Vector-borne pathogens include a wide range of organisms that are transmitted by a diverse set of species, including arthropods such as fleas, sandflies, ticks, and mosquitoes ${ }^{[1]}$. Mosquitoes are among the most serious insect vectors of medical importance and play an important role in disease transmission around the world ${ }^{[1,2]}$. They belong to family Culicidae (Order:
Diptera) and are vectors of many arthropodborne diseases such as malaria, yellow fever, and dengue; as well as they are debilitating agents to humans ${ }^{[1-3]}$. Annually, more than one million deaths are caused by vector-borne diseases, which account for more than $17 \%$ of all infectious diseases and affect our health and shape human societies $^{[4,5]}$. Malaria, caused by Plasmodium spp. parasites, which has the highest impact 
in terms of human deaths worldwide ${ }^{[4,6]}$. Malaria control campaigns in the 1950s1960s successfully eradicated the disease from the majority of the temperate regions ${ }^{[7]}$. However, the efforts of malaria control have suffered several dropbacks in the last decades, including the improvement of drug resistance in parasite populations and insecticide resistance in some of the major mosquito vectors $^{[8-10]}$.

Culex pipiens is a common and widely distributed mosquito worldwide, especially in Egypt ${ }^{[11-13]}$. It has been considered as the primary vector for Wuchereria bancrofti (a filarial nematode), one of the major public health problems in Egypt ${ }^{[14,15]}$. It is also the vector of West Nile and Sindbis viruses $^{[16]}$, Rift valley fever virus ${ }^{[17]}$, as well as serious nuisance pests. It is the most common mosquito species and breeds primarily in large numbers in receptacles that hold stagnant water and organic materials such as irrigation canals, drainage cesspools, sewage streams, and pit latrines ${ }^{[6,16]}$. These habitats provide shade, standing water, and decomposing organic material for mosquitoes. Even without rain, runoff from home sprinkling systems may provide enough water to facilitate mosquito breeding throughout the summer. Human infection with pathogens-transmitted by mosquitoes may lead to the onset of debilitating diseases, and due to limited vaccine availability ${ }^{[18]}$, mosquito control is essential to interrupt the transmission of these diseases. So, insecticides may play an essential role in controlling the major vectors of diseases, particularly mosquitoes.

Insecticides are substances used to kill insects $^{[18]}$. They include ovicides and larvicides used against insect eggs and larvae, respectively. Insecticides are claimed to be a major factor behind the increase in the $20^{\text {th }}$ century's agricultural productivity ${ }^{[19]}$. Nearly all insecticides have the potential to significantly alter ecosystems; many are toxic to humans and/or animals and some become concentrated as they spread along the food chain ${ }^{[20]}$. Insecticides can be classified into two major groups: systemic insecticides, which have residual or long-term activity; and contact insecticides, which have no residual activity. There are synthetic insecticides and natural insecticides; a major emphasis of organic chemistry is the development of chemical tools to enhance agricultural productivity. Synthetic insecticides such as dichlorodiphenyltrichloroethane (DDT, the bestknown organochloride) ${ }^{[21]}$ was created by Swiss scientist Paul Müller. For this discovery, he was awarded the Nobel Prize, in the year 1984, for Physiology or Medicine.

Other known classes of insecticides are organophosphates, pyrethroids, neonicotinoids, butenolides, and ryanoids. There are new generations of insecticides such as 1,2,4-triazine based insecticide, pymetrozine, which represents a novel insecticide with selective activity against aphids, whiteflies, and planthoppers ${ }^{[22]}$. By improvement adding methyl to the imine carbon and phenoxy group at the pyridine ring resulted in enhancement of their insecticidal activity against aphids and widening the activity against mosquitoes, lepidopteran cotton bollworm, corn borer, and oriental armyworm ${ }^{[23]}$. As insecticide discovery is of top priority, the present study aims to evaluate the effect of some 1,2,4-triazine derivatives on the survivorship and biology of the common mosquito " $C x$. pipiens".

\section{MATERIAL AND METHODS \\ Insects}

Egg-batches of $C x$. pipiens were sampled from an oviposition site in the medical campus of Tanta University (30 $48^{\circ} 5.339^{\prime \prime} \mathrm{N}$ latitude and 30 59'36.114"E longitude), Gharbia, Egypt. The collected egg batches were immediately transferred to an insectary at the Faculty of Science, Tanta University, and put separately in glass cups $(100 \mathrm{~mL}$ size) with distilled water. On hatching, $C x$. pipiens larvae were transferred into enamel pans (60 $\mathrm{cm}$ radius and $15 \mathrm{~cm}$ depth) containing distilled water, supplied with dry fish food flakes (TetraMin, Blacksburg, VA, USA). The mosquitoes were kept in 
laboratory conditions $\quad 27 \pm 2^{\circ} \mathrm{C}, \quad 70-80 \%$ relative humidity, and $12 \mathrm{~h}: 12 \mathrm{~h}$ dark:light photo-cycle. The third instar larvae (approximately 7 days from hatching) were identified using the key for Egyptian culicine mosquitoes $^{[12]}$. This stage is subject to experiments as seen below.

\section{Chemicals}

The derivatives of 1,2,4-triazine (MSA 25, $26,27,31,32,34,35$, and 102) used in the present study were synthesized as described previously ${ }^{[24]}$. Briefly, 4-amino-6[2-(4-methoxyphenyl)vinyl]-3-thioxo-3,4-dihydro-2H-[1,2,4]triazin-5-one (MSA 102) was obtained by the cyclized condensation between thiocarbohydrazide and 4-methoxybenzylidenepyruvic. Then MSA102 reacted with benzaldehyde, thiophene-2carboxyldehyde, and pyridine-2-carboxyldehyde to afford MSA 25, MSA 26, and MSA 27, respectively ${ }^{[24]}$. The 4-amino3-hydrazino-6-[2-(4-methoxyphenyl)vinyl]$4 \mathrm{H}-[1,2,4]$ triazin-5-one (MSA 31) was obtained from boiling MSA 102 with hydrazine hydrate. Then, MSA 31 reacted with benzaldehyde, thiophene-2-carboxyldehyde, and pyridine-2-carboxyldehyde to afford MSA 32, MSA 34, and MSA 35, respectively ${ }^{[24]}$. All 1,2,4-triazine based chemical compounds contain different high reactive functional groups were tested against $C x$. pipiens; the chemical structures and physical properties of the used triazine derivatives are shown in Table " 1 ". A reference insecticide "pymetrozine (TEDO 50\%WG, Shoura Co., Cairo, Egypt)" was used in the subsequent experiments as a positive control.

\section{Screening of several triazine derivatives against $C x$. pipiens $3^{\text {rd }}$ instar larvae}

In this experiment, the killing rate of 1,2,4triazine compounds: MSA 25, 26, 27, 31, 32, 34, 35, and 102 were tested against Cx. pipiens $3^{\text {rd }}$ instar larvae. In brief, $0.1 \mathrm{~g}$ of each compound was dissolved into $5 \mathrm{~mL}$ dimethylformamide (DMF) to prepare $20 \mathrm{~g} / \mathrm{L}$ solutions (stock). Ten $3^{\text {rd }}$ instar larvae were transferred into $100 \mathrm{~mL}$ distilled water contained $(0.4 \mathrm{~mL}$ of stock solution) to prepare $80 \mathrm{mg} / \mathrm{L}$ of the tested compounds, as a final concentration and based on our preliminary trials. The control was run only using $100 \mathrm{~mL}$ distilled with an equivalent amount of DMF ( $0.4 \mathrm{~mL}$ volume/volume). Larvae were supplied with dry fish food flakes. Mortality was recorded at 24 and 48 hours post-application. Three replicates per compound or the control were carried out. MSA 35 and 102 compounds caused the highest mortality results, so they were selected as insecticide candidates in the following experiments.

\section{Determination of the median lethal concentration $\left(\mathrm{LC}_{50}\right)$ of the selected compounds}

The bioassay of the $\mathrm{LC}_{50}$ was carried out in $100 \mathrm{~mL}$ distilled water cups as previously described $^{[25]}$. A series of MSA 35 and MSA 102 concentrations (0.2-0.8 mg/L) was prepared by dilution method. For the reference insecticide (pymetrozine), a stock solution $(50 \mathrm{mg} / \mathrm{L})$ was prepared by dissolving $0.1 \mathrm{~g}$ into $2.0 \mathrm{~L}$ of distilled water; the concentrations tested were $0.5,1,5,10$, and $20 \mathrm{mg} / \mathrm{L}$. The control was prepared by adding $5 \mu \mathrm{L}$ of DMF to $100 \mathrm{~mL}$ distilled water cup. Ten larvae of the $3^{\text {rd }}$ instar were used per replicate, five replicates were done per concentration. Dry fish food flakes were added to each cup. The mortality of larvae was recorded after 48 hours.

Estimation of the death rate in $C x$. pipiens exposed to $\mathrm{LC}_{50}$ of the insecticide candidates

In this experiment, groups of 60 larvae of $3^{\text {rd }}$ instar were placed in pans containing $1000 \mathrm{~mL}$ of distilled with $\mathrm{LC}_{50}$ of each compound. The $\mathrm{LC}_{50}$ values are $0.457,0.333$, and $2.047 \mathrm{mg} / \mathrm{L}$ for compounds MSA 35, MSA 102, and the reference insecticide, respectively. The control group was carried out using sixty $3^{\text {rd }}$ instar larvae in distilled water with $5 \mu \mathrm{L}$ DMF. The larvae were supplied with dry fish food flakes every two days till the end of the experiment. The mortality rate and time were observed for one-week post-treatment. 
Table 1: Chemical structures and physical properties of compounds understudy

\begin{tabular}{|c|c|c|c|c|}
\hline $\begin{array}{c}\text { Triazine } \\
\text { derivatives* }\end{array}$ & Chemical Structure & General Formula & $\begin{array}{c}\text { Melting } \\
\text { point }\left({ }^{\circ} \mathrm{C}\right)\end{array}$ & Color \\
\hline MSA 25 & & $\begin{array}{c}\mathrm{C}_{19} \mathrm{H}_{16} \mathrm{~N}_{4} \mathrm{O}_{2} \mathrm{~S} \\
364.421\end{array}$ & $242-244$ & Pale yellow \\
\hline MSA 26 & & $\begin{array}{c}\mathrm{C}_{17} \mathrm{H}_{14} \mathrm{~N}_{4} \mathrm{O}_{2} \mathrm{~S}_{2} \\
370.4487\end{array}$ & $262-264$ & Yellow \\
\hline MSA 27 & & $\begin{array}{c}\mathrm{C}_{18} \mathrm{H}_{15} \mathrm{~N}_{5} \mathrm{O}_{2} \mathrm{~S} \\
365.409\end{array}$ & $300-302$ & Yellow \\
\hline MSA 31 & & $\begin{array}{c}\mathrm{C}_{12} \mathrm{H}_{14} \mathrm{~N}_{6} \mathrm{O}_{2} \\
274.279\end{array}$ & $290-292$ & Dirty white \\
\hline MSA 32 & & $\begin{array}{c}\mathrm{C}_{19} \mathrm{H}_{18} \mathrm{~N}_{6} \mathrm{O}_{2} \\
362.386\end{array}$ & 230 & Pale yellow \\
\hline MSA 34 & & $\begin{array}{c}\mathrm{C}_{17} \mathrm{H}_{16} \mathrm{~N}_{6} \mathrm{O}_{2} \mathrm{~S} \\
368.413\end{array}$ & 255 & Yellow \\
\hline MSA 35 & & $\begin{array}{c}\mathrm{C}_{18} \mathrm{H}_{17} \mathrm{~N}_{7} \mathrm{O}_{2} \\
363.388\end{array}$ & $240-242$ & Yellow \\
\hline MSA 102 & & $\begin{array}{c}\mathrm{C}_{12} \mathrm{H}_{12} \mathrm{~N}_{4} \mathrm{O}_{2} \mathrm{~S} \\
276.07\end{array}$ & 250 & Dirty white \\
\hline Pymetrozine & & $\begin{array}{c}\mathrm{C}_{10} \mathrm{H}_{11} \mathrm{~N}_{5} \mathrm{O} \\
217.10\end{array}$ & 234 & White \\
\hline
\end{tabular}

*All compounds are completely soluble in dimethylformamide

Determination of the development and emergence of $C x$. pipiens exposed to $\mathrm{LC}_{50}$ of the insecticide candidates

By using the previous setting, an experiment to calculate the development time and emergence rate was performed. In brief after application of the $\mathrm{LC}_{50}$ of the insecticide candidate and the reference insecticide on the $3^{\text {rd }}$ instar larvae of $C x$. pipiens, we noticed the dead and survivors up to all survived pupae emerged as adults. So, pupae were collected in glass cups with distilled water and transferred into wooden emergence cages $(30 \times 30 \times 30 \mathrm{~cm})$ fully covered with mesh gauze.
Determination of the adult fecundity and egg hatchability of $C x$. pipiens survived $\mathbf{L C}_{50}$ exposure of insecticide candidates

The emerged adults from the previous experiments were sexed and collected in groups of five (two females + three males) in wooden cages covered with tulle. They are daily fed on $10 \%$ sucrose solution. Two days after adult emergence, the females were allowed to take a blood meal from a domestic pigeon. A cup with $100 \mathrm{~mL}$ distilled water was placed in each cage for oviposition. Egg-laying was observed for the next two weeks. The egg-rafts laid were daily collected and counted under an optical 
microscope $(\times 10)$ and let separately to hatch in a glass cup with distilled water. Larvae hatched from each raft were transferred into wide pans filled with water and were reared till being $3^{\text {rd }}$ instar larvae to be counted for hatch rate.

\section{Data analysis}

Data were expressed as mean \pm standard deviation $(\mathrm{M} \pm \mathrm{SD})$. The normality of response variables was evaluated using the Anderson-Darling test, and the homogeneity of variances was assessed using Bartlett's test. The $\mathrm{LC}_{50}$ values of the selected compounds were estimated by the probit analysis using the LDP line software ${ }^{[26]}$ based on the method of Finney ${ }^{[27]}$. GENMOD procedure was adopted to compare the response variables measured on $C x$. pipiens following treatment with the tested compounds. To avoid many zero values in the results of susceptibility and egg count in some groups, statistics were performed on $(\mathrm{Y}+1)$. For comparison, larval mortality and hatchability rates, binomial distribution, and a logit link function were used. For larval mortality and development time, gamma distribution and a log link function were used; while for fecundity, Poisson distribution and log link function were selected. In the case of a significant difference, post hoc analysis was performed using the Bonferroni test to control the family-wise error rate. These analyses were conducted using the statistical software $\mathrm{SAS}^{[28]}$.

\section{RESULTS}

\section{Effect of the synthesized triazine} derivatives on $C x$. pipiens larvae

In the current study, no mortality was recorded in the control group. GENMOD results showed that treatment, time, and their interactions affected significantly the $C x$. pipiens mortality rate $\left(F_{8,36}=23.04\right.$, $P<0.0001 ; F_{1,36}=43.86, P<0.0001 ; F_{8,36}=$ 4.42, $P=0.0008$ ). Mortality of larvae increased significantly by the compounds MSA 25, 26, 27, 34, 35, and 102 at 48 hours compared to those at 24 hours (Figure 1).
Statistical analysis showed that the tested compounds had different mortality rates at 24 and 48 hours $\left(F_{8,18}=9.01, P<0.0001\right.$; $\left.F_{8,18}=17.09, P<0.0001\right)$. In more detail, at 24 hours, all compounds except MSA 31 had higher $(P<0.0062$, Bonferroni multiple comparisons) mortality than the control. However, MSA 35 (at 24 hours) had higher $(P<0.0062)$ mortality than the other compounds. Whereas, after 48 hours, the tested compounds were categorized into two groups. The first group contained MSA 31 and 32 that had higher $(P<0.0062)$ mortality than that in the control. The second groups contained MSA 25, 26, 27, 34, 35 , and 102 that had higher $(P<0.0062)$ mortality than those in the first group.

Insecticidal activity of the tested compounds against $\boldsymbol{C} x$. pipiens larvae

The probit analysis of the mortality data caused by the tested compounds indicated that $\mathrm{LC}_{50}$ values were arranged as 0.333 , 0.457 , and $2.042 \mathrm{mg} / \mathrm{L}$ for MSA 102 , MSA 35, and the reference insecticide (pymetrozine), respectively (Table 2).

\section{Effect of $\mathbf{L C}_{50}$ of the insecticide candidates on larval mortality, one-week post-treatment}

The control groups did not show any death after one week of DMF application. GENMOD analysis showed a significant $\left(F_{3,12}=1114.37, \quad P<0.0001\right)$ difference among the means of mortality rate, a week post-treatment (Figure 2a). The pairwise comparisons between the treatments indicated that the tested compounds were significantly $(P<0.0001)$ different from each other and the control. The mortality rate was ascendingly arranged as MSA $102>$ pymetrozine > MSA 35 . In another view, the time required for death after application (lethal time) of each compound was shown in Figure " $2 b$ ". The lethal time showed compound-dependent $\left(F_{2,9}=68.93, \quad P<0.0001\right)$ manner. The lethal time of MSA 102 was the shortest (1.41 \pm 0.015$)$ compared with MSA 35 $(1.89 \pm 0.00)$ and the reference insecticide 


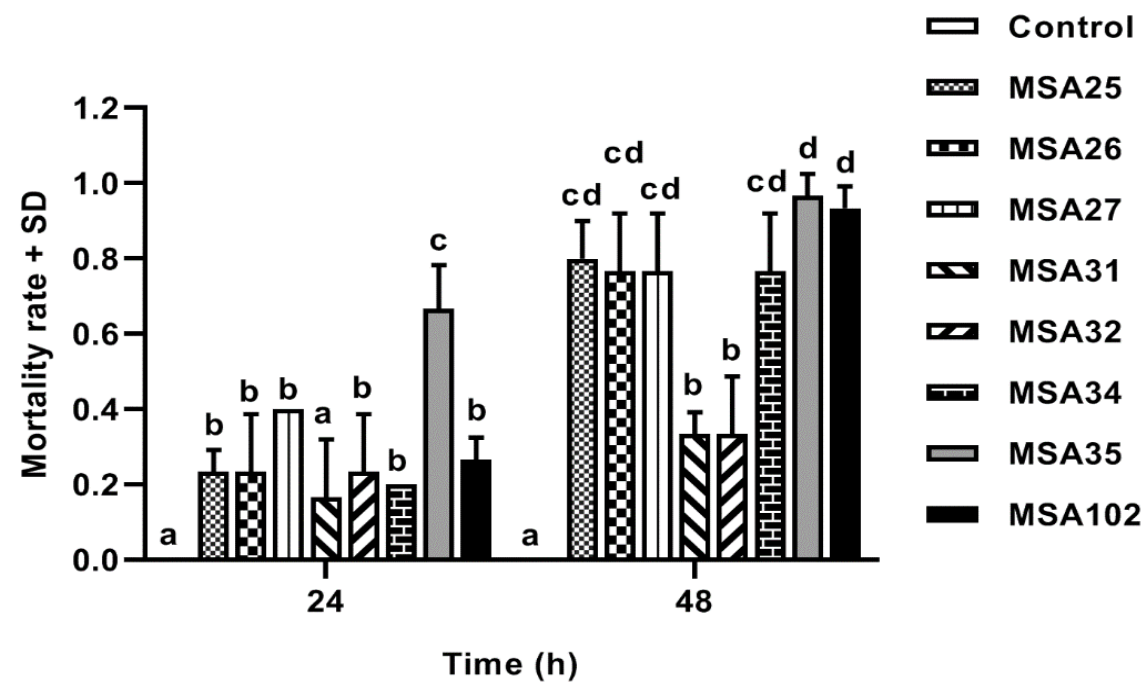

Figure 1: Mortality rate $(\mathrm{M}+\mathrm{SD})$ of Culex pipiens $3^{\text {rd }}$ instar larvae treated with $100 \mathrm{mg} / \mathrm{L}$ of different 1,2,4-triazine derivatives (MSA 25, 26, 27, 31, 32, 34, 35, and 102) after 24 and $48 \mathrm{~h}$. Bars with the different letters at the same time limit are significantly different (Bonferroni correction on multiple comparisons). h: hours; M: mean; SD: standard deviation.

Table 2: Insecticidal activity of two 1,2,4-triazine derivatives and a reference insecticide "pymetrozine" against $3^{\text {rd }}$ instar larvae of Culex pipiens after 48 hours of treatment.

\begin{tabular}{cccc}
\hline Compound name & $\begin{array}{c}\text { LC50 (mg/L) } \\
\text { (Fudicial limits) }\end{array}$ & Slope & Correlation coefficient $\left(\mathrm{R}^{2}\right)$ \\
\hline MSA 35 & $\begin{array}{c}0.457 \\
(0.392-0.531) \\
0.333\end{array}$ & $3.000 \pm 0.460$ & 0.967 \\
MSA 102 & $\begin{array}{c}0.285-0.378) \\
\text { 2.042 }\end{array}$ & \multirow{2}{*}{$1.147 \pm 0.150$} & 0.990 \\
Pymetrozine & $(1.370-2.879)$ & 0.949 \\
\hline
\end{tabular}
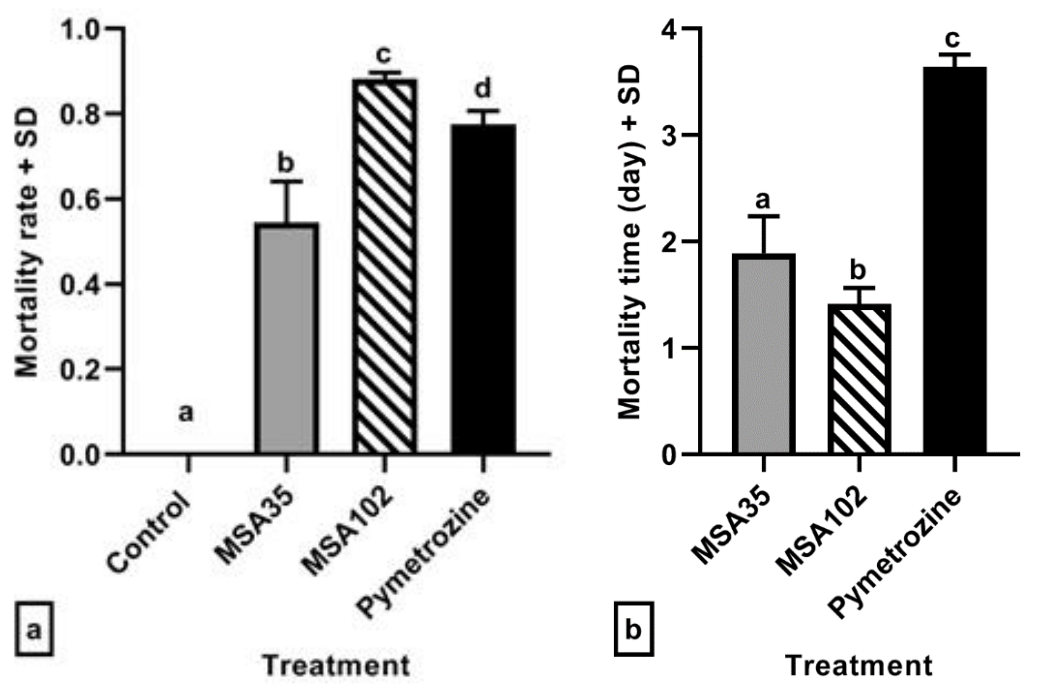

Figure 2: Effects of $\mathrm{LC}_{50}$ values of different 1,2,4-triazine derivatives on the mortality rate (a) and mortality time (b) of Culex pipiens $3^{\text {rd }}$ instar larvae. Data were expressed as mean \pm standard deviation $(\mathrm{M} \pm \mathrm{SD})$. Bars with the different letters at the same time limit are significantly different (Bonferroni correction on multiple comparisons). 
(3.64 \pm 0.011$)$. MSA 35 showed also shorter $(P<0.0001)$ lethal time compared with the reference insecticide (Figure 2b).

Effect of $\mathrm{LC}_{50}$ of the insecticide candidates on the development and emergence of $\boldsymbol{C} x$. pipiens

The development time of $C x$. pipiens since the exposure of $3^{\text {rd }}$ instar larvae to $\mathrm{LC}_{50}$ of MSA 35 and 102, as well the reference insecticide to adult emergence was shown in Figure " $3 \mathrm{a}$ ". The controls take $7.88 \pm 0.78$ days for development. Statistical analysis of development results after application indicated that the tested compounds influence the development time $\left(F_{3,12}=\right.$ 24.97, $P<0.0001)$. Multiple comparisons among the results of the development test

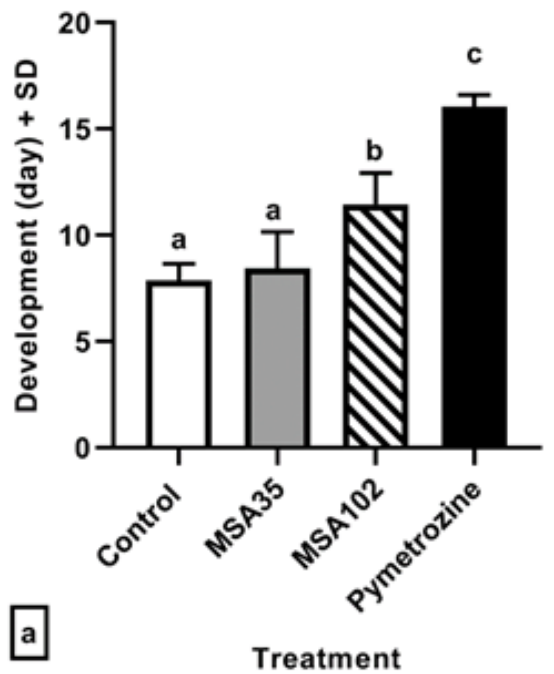

demonstrated that MSA 102 and the reference insecticide induced a significant $(P<0.0001)$ increase of development time, whereas MSA 35 only induced a slight nonsignificant $(P \geq 0.016)$ increase compared with the controls. The reference insecticide elongated the time required for development two-fold as that in the control.

The emergence rate of $C x$. pipiens showed a significant difference based on the compound used in the application $\left(F_{3,12}=\right.$ 87.51, $P<0.0001$ ) (Figure 3b). The results showed that all pupae formed in the control and reference-treated groups succeeded to emerge $100 \pm 0.00$. The significant difference in the GENMOD model was attributed to the significant $(P<0.0001)$ decrease in the emergence after the application of MSA 102.

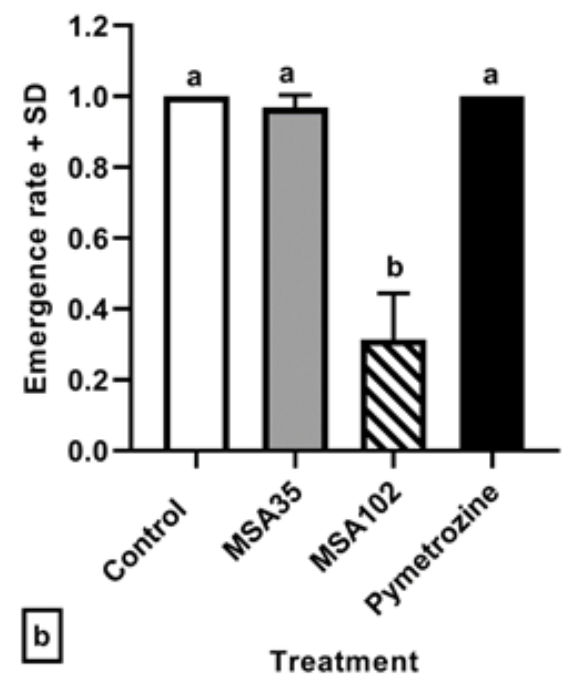

Figure 3: Effects of $\mathrm{LC}_{50}$ values of different 1,2,4-triazine derivatives on the development (a) and emergence rate $(\mathbf{b})$ of Culex pipiens $3^{\text {rd }}$ instar larvae. Data were expressed as mean \pm standard deviation $(\mathrm{M} \pm \mathrm{SD})$. Bars with the different letters at the same time limit are significantly different (Bonferroni correction on multiple comparisons).

Effect of $\mathrm{LC}_{50}$ of the insecticide candidates on the adult fecundity and egg hatchability of $\boldsymbol{C x}$. pipiens

The effects of 1,2,4-triazine compounds at $\mathrm{LC}_{50}$ on $C x$. pipiens adult fecundity and hatchability of eggs laid were shown in Figure "4". The control mosquitoes lay about $218 \pm 63 \mathrm{egg} / \mathrm{female/day.} \mathrm{Statistical}$ analysis of the adult fecundity results indicated that there is a significant difference among the means due to treatment $\left(F_{3,12}=\right.$ $37.04, \quad P<0.0001)$. This difference was attributed to the observed reduction in eggs laid by the females treated with MSA 102 compared with other treatments and the control. The $C x$. pipiens females treated with MSA 102 produced no eggs at all, whereas the females treated with MSA 35 or the reference insecticide showed a slight nonsignificant $(P \geq 0.016)$ reduction in the egg numbers (Figure 4a).

Regarding hatchability, the comparisons among the treated insects with MSA 35, reference insecticide, and the control group 
indicated significant differences $\left(F_{3,9}=8.84\right.$, $P=0.0075)$ (Figure 4b). This significant difference is attributed to the significant $(P<0.0137)$ reduction in hatch rate of eggs laid by adults that survived $\mathrm{LC}_{50}$ of MSA 35 compared with the control or the treated with reference insecticide. The hatch rate of the control eggs was 94.29 \pm 3.01 . The treatment with the reference insecticide showed a slight non-significant $(P \geq 0.016)$ decrease in the hatch rate compared with the control group.
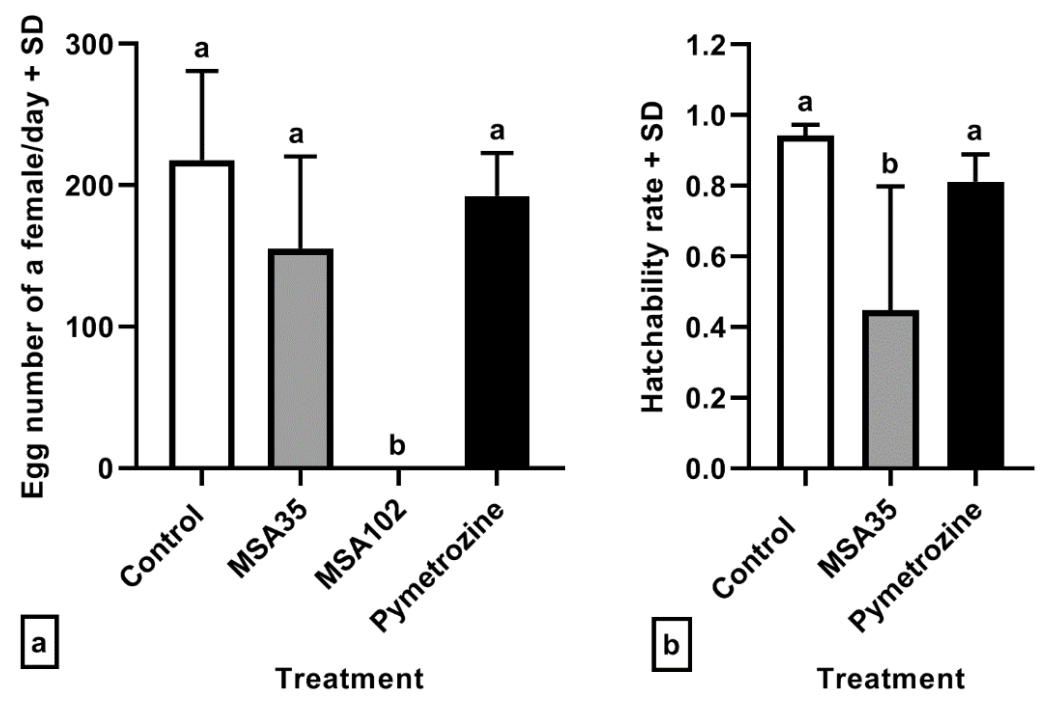

Figure 4: Effects of $\mathrm{LC}_{50}$ values of different 1,2,4-triazine derivatives on the adult female fecundity (a) and hatchability rate (b) of laid eggs by survived Culex pipiens. Data were expressed as mean \pm standard deviation $(\mathrm{M} \pm \mathrm{SD})$. Bars with the different letters at the same time limit are significantly different (Bonferroni correction on multiple comparisons).

\section{DISCUSSION}

In the current study, eight 1,2,4-triazine derivatives (MSA 25, MSA 26, MSA 27, MSA 31, MSA 32, MSA 35, and MSA 102) have been tested as insecticide candidates against $C x$. pipiens larvae. The results indicated that almost all compounds tested caused higher mortality in Cx. pipiens $3^{\text {rd }}$ instar larvae compared with the controls. Moreover, the mortality was higher at 48 hours than at 24 hours. These results are in agreement with Michaelakis et al. ${ }^{[29]}$ who reported that the mortality rates of alkannin and shikalkin at 24 hours in all applied doses (7-17 $\mathrm{mg} / \mathrm{L}$ ) was less than those observed at 48 hours after exposure. Similarly, Yang et $a l .{ }^{[23]}$ investigated some triazine derivatives and plant extracts, and found that 1,2,4triazine-based materials showed excellent larvicidal activities against mosquitoes. The higher reactivity of 1,2,4-triazine materials than other insecticides like fenitrothion, azadirachtin, cyphenothrin, and pyriproxyfen, which were used in much higher concentrations, was previously reported ${ }^{[30]}$. Similarly, Djeghader et al. ${ }^{[31]}$ reported that $20 \mathrm{mg} / \mathrm{L}$ of the plant-extracted saponin was needed to obtain high larval mortality in Cx. pipiens, which reflect the super reactivity of the 1,2,4-triazine based materials compared to the plant-extracted insecticides.

MSA 35 and MSA 102 compounds caused the highest mortality rate to Cx. pipiens larvae (approximately $97 \%$ and $93 \%$, respectively). Mahyoub et al ${ }^{[32]}$ also found that $0.01 \mathrm{~mL} / \mathrm{L}$ of Difox Flowable caused $95 \%$ of adult Cx. pipiens inhibition compared to $0.5 \mathrm{mg} / \mathrm{L}$ of Moskill4G, which caused $91 \%$. The $\mathrm{LC}_{50}$ values were 0.45 and $0.33 \mathrm{mg} / \mathrm{L}$ for MSA 35 and MSA 102, respectively, against the third instar larvae. The lethal concentration of the reference insecticide (pymetrozine) was $2.042 \mathrm{mg} / \mathrm{L}$. Traboulsi et al. ${ }^{[33]}$ also estimated the $\mathrm{LC}_{50}$ 
values of some plant extracts against Cx. pipiens larvae. The authors found that Foeniculum vulgare, Ferula hermonis, Citrus sinensis, and Pinus pinea had $\mathrm{LC}_{50}$ values of $24.5,44.0,60.0$, and $75.0 \mathrm{mg} / \mathrm{L}$, respectively.

One week after the application of $\mathrm{LC}_{50}$, the results demonstrated that toxicity of the tested compounds arranged ascendingly as MSA $102>$ pymetrozine > MSA 35. However, the order of lethal time indicated that MSA 102 killed $C x$. pipiens faster than MSA 35 and the reference insecticide. These results could be explained by the structure-property of the compounds. Chemically, MSA 102 has thioxo group that increases the toxicity of that material compared with MSA 35 and the reference insecticide ${ }^{[34]}$. Moreover, azo-pyridine unites of MSA 35 is linked with hydrazino unit, which is expected to make it more active compared with the reference insecticide ${ }^{[35]}$.

In this study, the effect of the potent candidates (MSA 35 and MSA 102) on $C x$. pipiens development and emergence of adults was investigated. The results showed that MSA102 and reference insecticide caused a delay in $C x$. pipiens development than the control group. Moreover, MSA 102 was the only compound that exhibited a reduction in adult emergence (31.4\%) compared with the control $(100 \%)$. Robert and Olson ${ }^{[36]}$ found that the $\mathrm{LC}_{50}$ of methoprene showed a significant effect on pupae-adult time in Cx. pipiens. Shu et al. ${ }^{[6]}$ also found that the lethal concentration of sodium, calcium hypochlorite prolonged the pupation time of $C x$. pipiens and caused a significant decrease in the adult emergence. Alto et al. ${ }^{[37]}$ found that malathion treatment had negative effects on development rate, survivorship to adulthood, body size (wing length), and longevity of $C x$. pipiens.

Regarding adult fecundity, the results showed that the treatment with $\mathrm{LC}_{50}$ of MSA 102 caused no egg-laying in $C x$. pipeins adult female. In hatchability, the treatment of MSA 35 was able to reduce the egg-hatchability of $C x$. pipiens compared to the control group or the reference insecticide. Similarly, Mohapatra et al. ${ }^{[38]}$ reported a significant decrease in the fecundity of $C x$. quinquefasciatus and An. stephensi after treatments with cyfluthrin and fenfluthrin. In addition, Kumar et $a .^{[39]}$ investigated the effect of deltamethrin on $C x$. pipiens and found a decrease in the laid eggs and hatching rate.

In conclusion, this study provides new information about the use of 1,2,4-triazine derivatives as new insecticide candidates. The 1,2,4-triazine-based compounds "MSA 102 and MSA 35" had better insecticidal activity than the reference insecticide "pymetrozine". Moreover, these 1,2,4triazine derivatives exhibited a reduction in larval development, adult emergence, fecundity, and hatchability compared to the control group. To develop a new insecticide, based on triazine derivatives, further studies are required to explore their mode of action in mosquitoes.

\section{ACKNOWLEDGEMENTS}

The authors thank Dr. Mohamed Shaker (Department of Chemistry, Faculty of Science, Tanta University) for the kind supply with the synthesized compounds.

\section{FUNDING SOURCE DISCLOSURE}

This work did not receive any fund.

\section{CONFLICT OF INTEREST}

The authors declare that they have no conflict of interest.

\section{AUTHORS' CONTRIBUTIONS}

MAS, MS \& WSM conceived the idea and designed the experiments. WN and MS collected data. WSM performed the statistical analysis. WN and MS wrote the drafts. MSA and WSM revised the manuscript. All authors approved the paper.

\section{REFERENCES}

[1] Sarwar, M. (2015). Insect borne diseases transmitted by some important vectors of class Insecta hurtling public health. International Journal of Bioinformatics and 
Biomedical Engineering, 1(3): 311317.

[2] Anosike, J. C.; Nwoke, B. E. B.; Okere, A. N. et al. (2007). Epidemiology of tree-hole breeding mosquitoes in the tropical rainforest of Imo State, south-east Nigeria. Ann Agric Environ Med, 14(1): 31-38.

[3] Shahen, M.; Guo, Z.; Shar, A. H. et al. (2018). Dengue virus causes changes of MicroRNA-genes regulatory network revealing potential targets for antiviral drugs. BMC Syst Biol, 12(1): 2 (DOI: 10.1186/s12918017-0518-x).

[4] Vector-Borne Diseases (2020). WHO (https://www.who.int/news-room/factsheets/detail/vector-borne-diseases).

[5] Farajollahi, A.; Fonseca, D. M.; Kramer, L. D. et al. (2011). "Bird biting" mosquitoes and human disease: a review of the role of Culex pipiens complex mosquitoes in epidemiology. Infect Genet Evol, 11(7): 1577-1585.

[6] Shu, Z.; Shahen, M.; Hegazi, M. A. M. et al. (2018). Physiological response of Culex pipiens larvae to sublethal concentrations of sodium and calcium hypochlorite. J Environ Biol, 39(3): 314-323.

[7] Li, X.-H.; Zhou, H.-N.; Xu, J.-W. et al. (2021). Seven decades towards malaria elimination in Yunnan, China. Malar J, 20: 147 (DOI: 10.1186/ s12936-021-03672-8).

[8] Susanna, D. and Pratiwi, D. (2021). Current status of insecticide resistance in malaria vectors in the Asian countries: a systematic review [version 1; peer review: 2 approved with reservations]. F1000Research, 10: $200 \quad$ (DOI: $10.12688 / \mathrm{f} 1000$ research.46883.1).

[9] Tan, W.-L.; Wang, Z.-M.; Li, C.-X. et al. (2012). First report on cooccurrence knockdown resistance mutations and susceptibility to betacypermethrin in Anopheles sinensis from Jiangsu Province, China. PLoS
One, 7(1): e29242 (DOI: 10.1371/ journal.pone.0029242).

[10] Meshrif, W. S.; Elhawary, N. A.; Soliman, M. A. et al. (2021). Insecticide resistance variation among three Culex pipiens (Diptera: Culicidae) populations in Egypt. Afr. Entomol, 29(2): 602-610.

[11] Selim, A. and Abdelhady, A. (2020). The first detection of anti-West Nile virus antibody in domestic ruminants in Egypt. Trop Anim Health Prod, 52(6): 3147-3151.

[12] Harbach, R. E. (1988). The mosquitoes of the subgenus Culex in southwestern Asia and Egypt (Diptera: Culicidae). Contrib Amer Ent Inst, 24(1): 1-240.

[13] Elhawary, N. A.; Soliman, M. A.; Seif, A. I. et al. (2020). Culicine mosquitoes (Diptera: Culicidae) communities and their relation to physicochemical characteristics in three breeding sites in Egypt. Egyptian Journal of Zoology, 74: 30-42.

[14] Southgate, B. A. (1979). Bancroftian filariasis in Egypt. Trop Dis Bull, 67(12): 1045-1063.

[15] Gad, A. M.; Shoukry, A.; El-Said, S. M. (1988). Vector competence to Wuchereria bancrofti in Culex pipiens collected from the Nile Delta. J Egypt Soc Parasitol, 18(1): 259-272.

[16] Samina, I.; Margalit, J.; Peleg, J. (1986). Isolation of viruses from mosquitoes of the Negev, Israel. Trans R Soc Trop Med Hyg, 80(3): 471-472.

[17] Brès, P. (1978). The Rift Valley fever virus, agent of dengue-like epidemics: its geographical distribution and public health problems. J Egypt Public Health Assoc, 53(3-4): 147-152.

[18] Duffy, P. E. (2021). Transmissionblocking vaccines: harnessing herd immunity for malaria elimination. Expert Rev Vaccines, 20(2): 185-198.

[19] Stephenson, G. R.; Ferris, I. G.; Holland, P. T. et al. (2006). Glossary of terms relating to pesticides (IUPAC 
Recommendations 2006). Pure Appl Chem, 78(11): 2075-2154.

[20] Hembrom, S.; Singh, B.; Gupta, S. K. et al. (2020). A Comprehensive Evaluation of Heavy Metal Contamination in Foodstuff and Associated Human Health Risk: A Global Perspective. In: Contemporary Environmental Issues and Challenges in Era of Climate Change (Singh, P.; Singh, R. and Srivastava, V. eds), pp. 33-63. Springer, Singapore.

[21] Mulliken, D. L.; Zambone, J. D. and Rolph, C. G. (2005). DDT: a persistent lifesaver. Nat resour environ, 19(4): 3-7.

[22] Hashem, H. E. (2021). A short review on the synthesis of 1,2,4-triazine derivatives as bioactive compounds. Mini Rev Org Chem, 18(8): 11271133.

[23] Yang, Y.; Liu, Y.; Song, H. et al. (2016). Additive effects on the improvement of insecticidal activity: design, synthesis, and insecticidal activity of novel pymetrozine derivatives. Bioorg Med Chem, 24(3): 391-402.

[24] El-Barbary, A. A.; Hafiz, Y. A. and Abdel-Wahed, M. S. (2010). Glycosylation, sugar hydrazones, and antimicrobial evaluation of some 6-substituted-1,2,4-triazines. Nucleosides Nucleotides Nucleic Acids, 29(1): 55-71.

[25] Guidelines for Laboratory and Field Testing of Mosquito Larvicides (2005). WHO (https://apps.who.int/ iris/handle/10665/69101).

[26] Bakr, E. (2007). LdP line (http://www.ehabsoft.com/ldpline).

[27] Finney, D. J. (1952). Probit Analysis: A Statistical Treatment of the Sigmoid Response Curve. Cambridge University Press, Cambridge, UK.

[28] SAS Institute Inc. (2004). SAS/STAT ( 9.1 User's Guide. SAS Institute Inc, Cary, NC, USA.

[29] Michaelakis, A.; Strongilos, A. T.; Bouzas, E. A. et al. (2009). Larvicidal activity of naturally occurring naphthoquinones and derivatives against the West Nile virus vector Culex pipiens. Parasitol Res, 104(3): 657-662.

[30] AL Zarog, A. A. and Elssaidi, M. A. (2007). Toxicity of some insecticides against mosquito larvae of Culex pipiens. Journal of Sebha University (Pure and Applied Sciences), 6(3): 4045.

[31] Djeghader, N.; Aïssaoui, L.; Amira, K. et al. (2018). Toxicity evaluation and effects on the development of a plant extract, the saponin, on the domestic mosquito, Culex pipiens. IJMR, 5(1): 01-05.

[32] Mahyoub, J. A.; Aziz, A.; Panneerselvam, C. et al. (2017). Seagrasses as sources of mosquito nano-larvicides? Toxicity and uptake of Halodule uninervis-biofabricated silver nanoparticles in dengue and Zika virus vector Aedes aegypti. J Clust Sci, 28(1): 565-580.

[33] Traboulsi, A. F.; El-Haj, S.; Tueni, M. et al. (2005). Repellency and toxicity of aromatic plant extracts against the mosquito Culex pipiens molestus (Diptera: Culicidae). Pest Manag Sci, 61(6): 597-604.

[34] Ray, S.; Smith, F. R.; Bridson, J. N. et al. (1994). Thiopyridyl triazine derivatives and their platinum complexes: a new class of potential antitumor agents. Inorganica chimica acta, 227(1): 175-179.

[35] Nigst, T. A.; Antipova, A. and Mayr, H. (2012). Nucleophilic reactivities of hydrazines and amines: the futile search for the $\alpha$-effect in hydrazine reactivities. J Org Chem, 77(18): 8142-8155.

[36] Robert L. L. and Olson J. K. (1989). Effects of sublethal dosages of insecticides on Culex quinquefasciatus. J Am Mosq Control Assoc, 5(2): 239-246.

[37] Alto, B. W.; Muturi, E. J. and Lampman, R. L. (2012). Effects of 
nutrition and density in Culex pipiens. Med Vet Entomol, 26(4): 396-406.

[38] Mohapatra, R.; Ranjit, M. and Dash A. (1999). Evaluation of cyfluthrin and fenfluthrin for their insecticidal activity against three vector mosquitoes. J Commun Dis, 31(2): 91-99.
[39] Kumar, S.; Thomas, A. and Samuel, T. (2009). Diminished reproductive fitness associated with the deltamethrin resistance in an Indian strain of dengue vector mosquito, Aedes aegypti L. Trop Biomed, 26(2): 55-64.

\section{How to cite this article:}

Nagaa, W.; Shahen, M.; Soliman, M. A. and Meshrif, W. S. (2022). Effect of 1,2,4-triazine derivatives against the mosquito "Culex pipiens" and its biological characteristics. Egyptian Journal of Zoology, 77: 1-13 (DOI: 10.21608/ejz.2021.106471.1065). 


\section{تأثير مشتقات الترايازين على بعوضة ”CULEX PIPIENS“) وخصائصها البيولوجية}

\section{ولاء نجا، محمد شاهين، محمد على سليمان ، وسام صلاح الدين مشرف}

قسم علم الحيوان، كلية العلوم، جامعة طنطا، غربية، مصر

تعتبر ناقلات الأمراض مصدر قلق خطير في البلدان النامية مثل مصر. ولذلك أجريت الدراسة الحالية لتقييم فاعلية

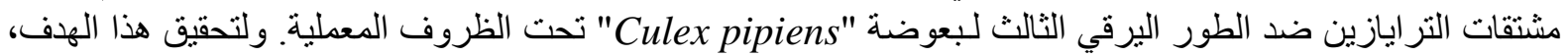

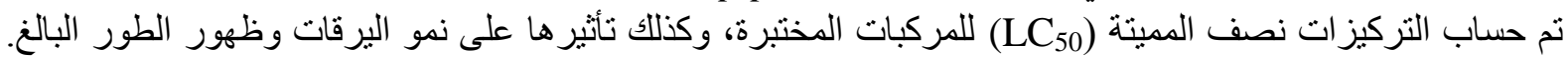

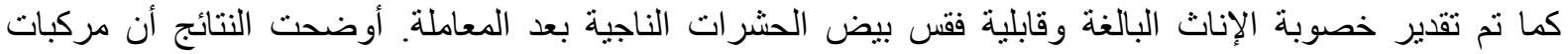

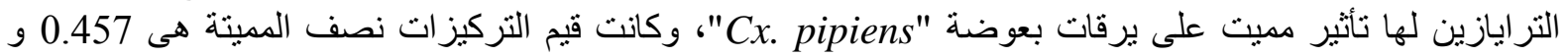

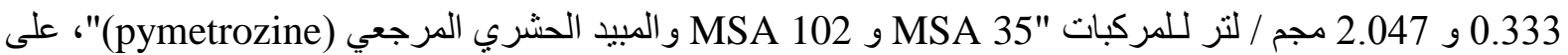

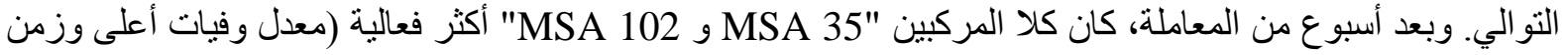

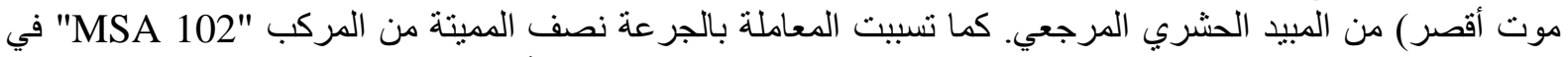

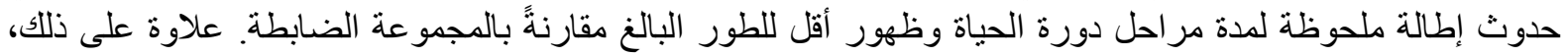

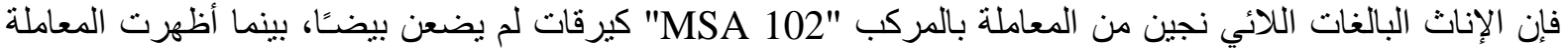

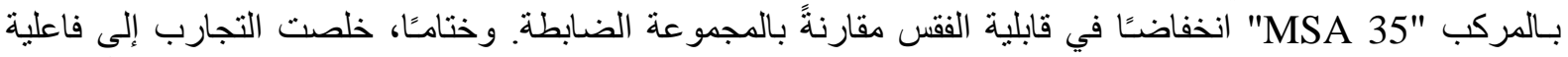

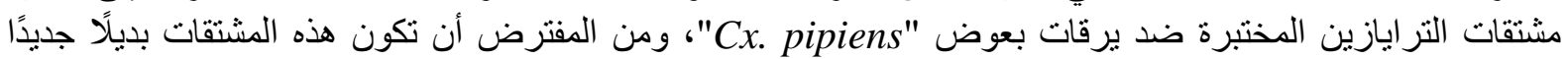

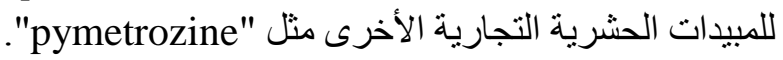

